\title{
Kontribusi dukungan sosial terhadap subjective well-being pada remaja dari keluarga etnis Minang
}

\author{
Rizki Pramisya $^{(1)}$, Tesi Hermaleni ${ }^{(2)}$
}

${ }^{(1),(2)}$ Fakultas Ilmu Pendidikan, Jurusan Psikologi, Universitas Negeri Padang, Padang, Indonesia

\begin{abstract}
Subjective well-being is a lynchpin for people's quality of life, but cultural factors may determine its dynamics. We conducted the present work within the cultural context of Minang people in West Sumatera, aimed as an empirical test on the role of social support in explaining subjective well-being among members of the ethnic group. We recruited 323 Minang adolescents aged between 15 and 19 years in West Sumatera. We found as hypothesised that social support positively and significantly explained subjective well-being wherein more social support was related to more subjective wellbeing $(r=.51, p<.001)$. Previous research zoomed in on the positive relationship between social support and subjective well-being particularly within the context of individualistic culture. What has been found in our work hence may serve as an alternative to the existing research in which we observed that even within the context of the collective culture of Minang people in West Sumatera, social support positively contributed to subjective well-being.
\end{abstract}

Keywords: adolescents aged 15-19 years, Minang culture, social support, subjective well-being

Kesejahteraan hidup menentukan kualitas hidup individu, tetapi dinamikanya mungkin dipengaruhi oleh faktor kebudayaan. Penelitian ini dilakukan dalam konteks budaya etnis Minang di Sumatera Barat dengan tujuan menguji peran dukungan sosial dalam menjelaskan kesejahteraan subjektif. Partisipan dalam penelitian ini terdiri dari 323 remaja berusia antara 15 sampai 19 tahun di Sumatera Barat, yang direkrut atas dasar purposive sampling. Sesuai dengan hipotesis yang diajukan, hasil penelitian menunjukkan bahwa dukungan sosial berperan signifikan dalam menjelaskan kesejahteraan hidup dimana semakin tinggi dukungan sosial maka semakin tinggi kesejahteraan hidup $(r=.51, p<$ .001). Riset-riset sebelumnya menekankan bahwa hubungan positif antara dukungan sosial dan kesejahteraan hidup lebih umum ditemukan dalam budaya individualistik. Menjadi alternatif riset-riset sebelumnya, hasil penelitian ini mengimpilikasikan bahwa dalam budaya kolektif etnis Minang di Sumatera Barat, dukungan sosial berkontribusi positif dalam meningkatkan kesejahteraan hidup.

Kata Kunci: budaya Minang, dukungan sosial, kesejahteraan sosial, remaja usia 15-19 tahun

MEDIAPSI, 2021, Vol. 7(1), 76-88, DOI: https://doi.org/10.21776/ub.mps.2021.007.01.8

Received: 28-01-2021. Revised: 02-02-2021. Accepted: 08-03-2021. Published online: 24-06-2021

Handling Editor: Sukma Nurmala, Universitas Brawijaya, Malang, Indonesia

*Corresponding author: Rizki Pramisya, Fakultas Ilmu Pendidikan, Universitas Negeri Padang, Padang, Indonesia.

E-mail: rzkpramisya@gmail.com

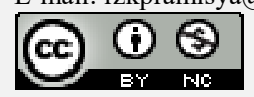

This work is licensed under a Creative Commons Attribution-NonCommercial 4.0 International License.

How to cite this article in accordance with the American Psychological Association (APA) $7^{\text {th }}$ guidelines:

Pramisya, R., \& Hermaleni, T. (2021). Kontribusi dukungan sosial terhadap subjective well-being pada remaja dari keluarga etnis Minang. MEDIAPSI, 7(1), 76-88. https://doi.org/10.21776/ub.mps.2021.007.01.8

\section{Pendahuluan}

\begin{tabular}{llr}
\multicolumn{2}{c}{ Minangkabau dikenal } & dengan \\
budaya kolektif yang & bercirikan \\
kekompakan dan kebersamaan & dalam \\
masyarakat (Yulanda, 2015). & Orang \\
Minangkabau juga dikenal & sebagai
\end{tabular}

masyarakat berbudaya matrilineal yang memiliki sistem pewarisan atas dasar garis keturunan Ibu (Zainal, 2014). Firdaus dkk. (2018) menjelaskan bahwa terdapat setidaknya tiga tipologi keluarga pada 
suku Minangkabau, yang mencakup (1) pasangan ayah dan ibu beretnis Minang, (2) pasangan ayah beretnis Minang dan ibu beretnis selain Minang, serta (3) pasangan ayah beretnis selain Minang dan ibu beretnis Minang. Terlepas dari ragam tipologi tersebut, keluarga Minang mendidik anak-anak mereka mengenai pentingnya bersosialisasi di lingkungan masyarakat.

Pasangan ayah dan ibu beretnis Minang menanamkan kepada anak-anak mereka nilai kebersamaan dan kesetiakawanan. Pasangan ayah beretnis Minang dan ibu beretnis selain Minang menekankan pentingnya kemampuan beradaptasi dengan lingkungan sosial. Sementara itu, pasangan ayah beretnis selain Minang dan ibu beretnis Minang menanamkan sikap gotong royong agar anak-anak tidak tumbuh menjadi individu yang egois. Oleh karena itu, peneliti dapat menyimpulkan bahwa pada budaya kolektif, orangtua turut serta dalam kehidupan sosial yang dapat mempengaruhi kepuasan hidup individu.

Kesejahteraan hidup memiliki sejumlah aspek, yang salah satunya adalah kepuasan hidup. Dalam psikologi, kesejahteraan hidup dikenal dengan sebutan subjective well-being, yang diringkas dengan istilah SWB. SWB adalah persepsi dan evaluasi kognitif individu terhadap pengalaman positif dan negatif kehidupan mereka baik kehidupan saat ini maupun masa lampau (Diener dkk., 2015; Proctor, 2014). Andrews dan Withey (1976) mengemukakan bahwa SWB tersusun dari tiga komponen. Komponen pertama adalah kepuasan hidup dari evaluasi kognitif terhadap keseluruhan kehidupan individu, komponen kedua adalah adanya pengalaman emosional MEDIAPSI | 2021, Vol. 7, No. 1, 76-88 positif (afeksi positif), dan komponen ketiga adalah tidak adanya pengalaman emosional negatif (afeksi negatif).

Suh dan Oishi (2002) menjelaskan bahwa individu yang hidup dalam budaya individualistik memiliki kesejahteraan hidup yang lebih tinggi dibanding individu yang hidup di budaya kolektif. Alasannya, budaya individualistik mendukung individu memperoleh kebebasan sesuai dengan keinginannya sendiri, sedangkan budaya kolektivistik lebih cenderung menitikberatkan nilai sosial atau kebersamaan. Diener dkk. (2015) juga menyatakan, individu yang tinggal di budaya individualistik cenderung melaporkan tingkat kepuasan diri sendiri yang tinggi tetapi tingkat kepuasan hidup mereka secara global cenderung rendah. Sebaliknya, individu di budaya kolektifistik cenderung tinggi tingkat kepuasaan hidup mereka secara global tetapi tingkat kepuasan diri mereka cenderung rendah. Keterlibatan orangtua dan budaya, dengan demikian, mempengaruhi kesejahteraan hidup, khususnya pada remaja (Jach dkk., 2018; Tov \& Diener, 2013).

Remaja adalah individu yang berproses dari masa kanak-kanak menuju masa dewasa. Transisi perkembangan ini dipengaruhi oleh berbagai faktor, seperti faktor keturunan atau biologi dan lingkungan atau masyarakat (Santrock, 2018). Menurut Hazen dkk. (2008), remaja akan mengalami perubahan dalam segala aspek kehidupan, seperti fisik, emosi, kognisi, dan moral. Friedman (1999) mengatakan bahwa perkembangan remaja dipengaruhi oleh budaya; remaja yang berasal dari budaya individualistik akan lebih mandiri dibandingkan remaja yang berasal dari budaya kolektif. 
SWB juga ditentukan oleh status sosial dan ekonomi, jenis kelamin, variabel-variabel demografis seperti kepribadian (neurotisme, ekstroversi), kecerdasan (nilai hasil pembelajaran yang diharapkan), dan harapan, serta dukungan orangtua (Steinmayr dkk., 2019). Dukungan dari orangtua berhubungan positif secara signifikan dengan SWB dan dukungan dari teman. Sementara itu, pada remaja, dukungan orang spesial seperti kekasih tidak menjadi prediktor terhadap SWB (Gülaçti, 2010). Temuan ini berbanding terbalik dengan sejumlah penelitian sebelumnya (Diener dkk., 2018; Gallagher \& Vella-Brodrick, 2008; Xi dkk., 2017), yang menjelaskan bahwa dukungan sosial baik dari keluarga maupun teman sebaya berhubungan positif secara signifikan dengan SWB.

Hasil-hasil penelitian diatas merefleksikan adanya peran dukungan sosial dalam menjelaskan $S W B$ di kalangan remaja. Temuan tersebut selaras dengan hasil penelitian pendahuluan yang dilakaukan oleh peneliti. Dalam penelitian pendahuluan ini, yang dilakukan di bulan Februari 2020 kepada 49 remaja dari keluarga etnis Minang, peneliti menemukan bahwa $94 \%$ responden menyatakan pentingnya dukungan sosial, 49\% menyatakan pentingnya dukungan dari keluarga sangat dibutuhkan, dan 43\% menyatakan pentingnya dukungan dari teman sebaya.

Sarafino (2002) menjelaskan, dukungan sosial termanifestasi dalam beberapa konstruk, yang mencakup perhatian, penghargaan, dan kenyamanan, serta pertolongan yang diterima oleh individu. Zimet dkk. (1988) berpendapat bahwa dukungan sosial dipersepsikan sebagai cara individu dalam menafsirkan MEDIAPSI | 2021, Vol. 7, No. 1, 76-88 sumber dukungan yang berasal dari orang yang signifikan atau orang terdekat. Zimet dkk. (1988) juga menjelaskan aspek dari dukungan sosial, yaitu dukungan keluarga, dukungan teman, dan dukungan dari orang yang istimewa. Terdapat empat macam dukungan sosial menurut Sarafino (2002), yang mencakup (1) emotional or esteem support sebagai bentuk dukungan sosial yang mengarah pada pemberian perhatian dan rasa peduli kepada individu, (2) instrumental support sebagai bantuan langsung yang diberikan seseorang kepada individu, (3) informational support, yaitu dukungan dalam bentuk saran, arahan, nasehat, masukan, dan umpan balik tentang apa yang dilakukan individu, dan (4) companionship support atau dukungan dalam bentuk waktu, kebersamaan, dan hubungan sosial yang dilakukan bersama individu.

Aspek kehidupan yang banyak berubah pada masa remaja membuat stressor tersendiri bagi seorang remaja, sehingga dukungan sosial sangat dibutuhkan terutama dalam bentuk dukungan emosional (Camara dkk., 2017). Tian dkk. (2015) dalam penelitiannya menjelaskan bahwa dukungan sosial baik dari orangtua, guru, serta teman memengaruhi SWB remaja. Untuk itu, peneliti melakukan penelitian lebih lanjut mengenai keterkaitan dukungan sosial terhadap SWB pada remaja dari keluarga etnis Minangkabau. Belum ada riset sebelumnya yang mengaitkan hubungan dukungan sosial dan SWB dengann unsur budaya, terutama dalam konteks budaya Minangkabau. Mengacu pada teori-teori dan temuan-temuan penelitian sebelumnya, hipotesis yang diajukan dalam penelitian ini menyatakan bahwa dukungan sosial berperan signifikan dalam 
menjelaskan tingginya subjective wellbeing di kalangan remaja dari keluarga etnis Minang.

\section{Metode}

Partisipan dan desain penelitian

Populasi penelitian ini ialah remaja di Sumatera Barat. Berdasarkan data dari kementerian pendidikan dan kebudyaan ("Jumlah data satuan pendidikan [sekolah] per provinsi: Prov. Sumatera Barat", 2019), siswa SMA dan SMK se-Provinsi Sumatera Barat tahun ajaran 2019/2020 berjumlah 150.405. Hurlock (2003) membagi remaja menjadi 3 kelompok usia, yaitu (1) early adolescene atau remaja awal dalam rentang usia 12-15 tahun, (2) middle adolescene atau remaja pertengahan dalam rentang usia 15-18 tahun, dan (3) late adolescene atau remaja akhir dalam rentang usia 18-21 tahun.

Menggunakan purposive sampling, sampel peneltiian ditentukan atas dasar karakteristik yang sudah ditentukan sesuai dengan kebutuhan penelitian (Winarsunu, 2012). Kriteria sampel penelitian terdiri dari (a) remaja yang berasal dari keluarga etnis Minang yaitu ayah dan ibu Minang atau ibu Minang dan ayah non-Minang, (b) siswa sekolah menengah atas (SMA) dan sekolah menengah kejuruan (SMK) di Sumatera Barat, serta (c) domisili di Sumatera Barat.

Sampel penelitian berjumlah 323. Dari total sampel ini, 78 berjenis kelamin laki-laki (24\%) dan 245 berjenis kelamin perempuan (76\%). Rentang usia sampel adalah 15-19 tahun $(M=16.43, S D=0.99)$. Sebaran data berdasarkan domisili subjek penelitian ditampilkan dalam Tabel 1 sebagai berikut:

Tabel 1. Data Sebaran Subjek Penelitian.

\begin{tabular}{lcc}
\hline Kabupaten/kota & $N$ & Persentase (\%) \\
\hline Padang & 74 & $23 \%$ \\
Bukittinggi & 60 & $19 \%$ \\
Solok & 42 & $13 \%$ \\
Pariaman & 24 & $7 \%$ \\
Batusangkar & 6 & $2 \%$ \\
Sijunjung & 8 & $3 \%$ \\
Payakumbuh & 35 & $11 \%$ \\
Pesisir Selatan & 23 & $7 \%$ \\
Lima Puluh Kota & 7 & $2 \%$ \\
Dharmasraya & 8 & $3 \%$ \\
Pasaman Barat & 6 & $2 \%$ \\
Padang Panjang & 10 & $3 \%$ \\
Agam & 20 & $6 \%$ \\
\hline Keterangar $N$ & & \\
\hline
\end{tabular}

Keterangan. $\quad N=$ jumlah sampel untuk masing-masing kabupaten atau kota di Sumatera Barat.

Penelitian ini menggunakan pendekatan kuantitatif, khususnya deskriptif korelasional (Sangadji \& Sophia, 2010). Desain penelitian tersebut bertujuan untuk mengetahui kontribusi dukungan sosial sebagai variabel independen (X) terhadap subjective wellbeing atau SWB sebagai variabel dependen (Y), serta untuk mengetahui indeks determinasi atau kesesuaian model penelitian dengan data yang diperoleh (Sugiarti \& Megawarni, 2012).

\section{Prosedur dan pengukuran}

Data penelitian dikumpulkan dengan dua skala. Pertama adalah skala dukungan sosial dari Fahmi (2019) yang merujuk pada Multidimensional Scale of Perceived Social Support (MSPSS) yang dikembangkan oleh Zimet dkk. (1988). Zimet dkk. (1988) menyatakan bahwa dukungan sosial meliputi tiga aspek utama, 
yaitu dukungan dari keluarga, dukungan dari teman, dan significant other. Skala penelitian dukungan sosial terdiri dari 12 aitem dengan pembagian 4 aitem untuk dukungan dari keluarga, 4 aitem dukungan dari teman, dan 4 aitem untuk significant other. Berdasarkan uji reliabilitas diperoleh nilai Cronbach's alpha sebesar $\alpha$ $=.91$.

Skala SWB atau subjective wellbeing menggunakan skala dari Utami dkk. (2018) yang merujuk pada, pertama, Satisfaction with Life Scale (SWLS) dari Diener dkk. (1985) untuk mengukur kepuasan hidup. Kedua adalah skala Positive and Negative Affect Schedule (PANAS) dari Watson dkk. (1988) untuk mengukur tingkat afek positif dan negatif pada suatu waktu. Skala ini terdiri dari 55 aitem yang terdiri dari afek positif (6 aitem), afek negatif (25 aitem), dan kepuasan hidup (24 aitem). Skala SWB memiliki reliabilitas Cronbach's alpha sebesar $\alpha=.90$.

Kedua skala dalam penelitian ini menggunakan skala Likert dengan 5 kategori jawaban, yang bervariasi mulai dari 1 (sangat tidak sesuai) hingga 5 (sangat sesuai) untuk skala dukungan sosial, dan 1 (sangat tidak puas) hingga 5 (sangat puas) untuk skala SWB.
Pengumpulan data menggunakan kuesioner daring dengan bantuan google form. Penyebaran data awal diperuntukkan untuk menguji reliabilitasi serta untuk melihat apakah terdapat aitem gugur dalam skala penelitian yang diadaptasi. Aitemaitem skala dukungan sosial tidak ada yang gugur, sementara 21 aitem untuk skala SWB dinyatakan gugur dan menyisakan 55 aitem yang mewakili 3 aspek. Setelah tahap seleksi aitem ini, kedua skala disebarkan ke 409 responden. Dari total responden ini, 323 yang dianalisis setelah mengeksklusi beberapa responden yang tidak sesuai dengan kriteria dan memgandung outliers.

\section{Hasil}

Hipotesis dalam penelitian ini diuji dengan regresi linier sederhana. Sebelum melakukan analisis ini, dua langkah dilakukan terlebih dahulu. Langkah pertama adalah membuat kategorisasi tingkatan dukungan sosial dan subjective well-being pada remaja dari keluarga etnis Minang. Kategorisasi data dilakukan berdasarkan teori yang dikemukakan oleh Azwar (2012). Adapun kategorisasi kedua variabel dijabarkan pada Tabel 2 sebagai berikut.

Tabel 2. Kategorisasi Data Dukungan Sosial dan Subjective Well-Being.

\begin{tabular}{ccccc}
\hline Kategori & Dukungan sosial & $N$ & $\begin{array}{c}\text { Subjective well-being } \\
(\text { SWB })\end{array}$ & $N$ \\
\hline Tinggi & $\mathrm{X}<28$ & 170 & $\mathrm{X}<-21.67$ & 142 \\
Sedang & $28 \leq \mathrm{X}<44$ & 142 & $-21.67 \leq \mathrm{X}<51.67$ & 181 \\
Rendah & $44 \leq \mathrm{X}$ & 11 & $51.67 \leq \mathrm{X}$ & - \\
\hline
\end{tabular}

Keterangan. $N=$ jumlah responden penelitian untuk masing-masing kategori dukungan sosial dan subjective well-being. 
Tabel 2 di atas menunjukkan bahwa tingkat dukungan sosial pada 170 (53\%) remaja berada pada kategori tinggi, 142 (44\%) remaja berada kategori sedang, dan $11(3 \%)$ remaja berada pada kategori rendah. Terkait dengan tingkat SWB, hasil menunjukkan bahwa 142 (44\%) remaja berada pada kategori tinggi dan 181 (56\%) remaja berada pada kategori sedang. Hasil ini menunjukkan bahwa remaja dari keluarga etnis Minang memiliki nilai $S W B$ yang mencukupi.

Langkah kedua, mengacu Ghazali (2011), adalah melakukan uji normalitas dan uji linieritas. Uji normalitas menggunakan Kolmogorov-Smirnov Test, dimana data dikatakan terdistribusi normal apabila nilai asymptote variabel bernilai tidak signifikan atau $p$ lebih besar dari .05 (Priyatno, 2013). Hasil menunjukkan bahwa data dalam penelitian ini berdistribsi normal, sebagaimana ditampilkan pada Tabel 3 di bawah ini.

Sementara itu, Sudarmanto (2005) menyatakan bahwa hubungan antara dua variabel dinyatakan linear apabila nilai deviation from linearity bernilai tidak signifikan. Hasil menunjukkan bahwa hubungan antara kedua variabel dalam penelitian ini, yaitu dukungan sosial dan subjective well-being atau SWB adalah liniear, sebagaimana bisa dicermati dalam Tabel 4 di bawah ini.

Tabel 3. Uji Normalitas.

\begin{tabular}{ccccc}
\hline & \multicolumn{4}{c}{ Dukungan Sosial } \\
& $N$ & Asymptote & K-SZ & Ket. \\
\hline Subjective Well-Being & 323 & .20 & .04 & Normal \\
\hline
\end{tabular}

Keterangan. $\mathrm{N}=$ jumlah responden dalam penelitian. $\mathrm{K}-\mathrm{SZ}$ = nilai uji normalitas Kolmogorov-Smirnov Test.

Tabel 4. Uji Linearitas.

\begin{tabular}{lcccc}
\hline & \multicolumn{4}{l}{ Dukungan sosial } \\
& $N$ & $d f$ & $F$ & $p$ \\
\hline Subjective Well-Being & 323 & 1 & 1.14 & .273 \\
\hline
\end{tabular}

Keterangan. $N=$ jumlah responden dalam penelitian. $d f=$ derajat bebas. $p=$ nilai signifikansi.

Tabel 5. Uji Regresi Linear Sederhana.

\begin{tabular}{cccccc}
\hline Variabel & $R$ & $R^{2}$ & $B$ Constant & $B$ & $p$ \\
\hline Dukungan sosial & .51 & .26 & 24.04 & .59 & $<.001$ \\
\hline Keterangan $R^{2}=$ kofisien
\end{tabular}

Keterangan. $R^{2}=$ koefisien determinasi. $B=$ koefisien regresi tidak terstandarisasi. $p=$ nilai signifikansi. 
Setelah mendapatkan hasil dari kedua uji tersebut, selanjutnya peneliti melakukan uji hipotesis penelitian atas dasar analisis regresi linear sederhana, yang hasilnya ditampilkan pada Tabel 5 di atas.

Hasil di atas menunjukkan bahwa, mendukung hipotesis yang diajukan, peran dukungan sosial terhadap subjective well-being adalah signifikan. Langkah berikutnya, mengacu pada Yuliara (2016), adalah mentranformasi hasil regresi liniear sederhana tersebut ke dalam persamaan sebagai berikut:

$$
\dot{Y}=a+b X(1)
$$

Huruf $a$ dalam rumus pertama di atas adalah nilai $B$ constant, dimana pada tabel diperoleh hasil sebesar 24.04. Nilai konstan ini memiliki arti bahwa jika seorang remaja dari keluarga etnis Minang tidak memperoleh dukungan sosial, maka nilai $S W B$ pada remaja tersebut adalah sebesar 24.04. Nilai $b$ pada rumus pertama di atas dikenal dengan sebutan angka koefisien regresi (B). Tabel 5 menunjukkan nilai $B$ sebesar 0.59 , yang berarti jika dukungan sosial yang diberikan meningkat sebanyak 1\% kepada remaja, maka SWB remaja akan meningkat sebanyak 0.59. Berdasarkan uraian hasil nilai konstanta dan koefisien regresi tersebut, rumus persamaan analisis regresi linear sederhana dalam penelitian ini ditentukan sebagai berikut:

$$
S W B=24.04+0.59 X(2)
$$

Terakhir, tetap mengacu pada Tabel 5 , nilai koefisien determinasi $\left(R^{2}\right)$ peran dukungan sosial terhadap SWB adalah sebesar .26, yang mengandung arti bahwa dukungan sosial berpengaruh secara positif dan berkontribusi sebanyak $26 \%$ terhadap SWB pada remaja dari keluarga etnis Minang.

Peneliti ini secara eksploratoris juga menguji peran jenis kelamin terhadap perbedaan tingkat dukungan sosial dan SWB, yang hasilnya ditampilkan dalam Tabel 6 di sebagai berikut:

Tabel 6. Uji Perbedaan Berdasarkan Jenis Kelamin.

\begin{tabular}{lcccc}
\hline \multicolumn{1}{c}{ Variabel } & $\mathrm{JK}$ & $M$ & $N$ & $p$ \\
\hline Subjective well-being & $\mathrm{L}$ & 50.99 & 78 & .993 \\
(SWB) & $\mathrm{P}$ & 49.99 & 245 & \\
Dukungan sosial & $\mathrm{L}$ & 43.39 & 78 & .556 \\
\hline
\end{tabular}

Keterangan. $\mathrm{JK}=$ jumlah kuadrat. $M=$ rata-rata. $N=$ jumlah sampel. $\mathrm{L}=$ responden laki-laki. $\mathrm{P}=$ responden wanita. $p=$ nilai signifikansi.

Tabel 6 di atas menunjukkan bahwa tidak terdapat perbedaan signifikan SWB dan dukungan sosial dilihat dari segi jenis kelamin.

\section{Diskusi}

Hasil uji hipotesis dalam penelitian ini menunjukkan adanya hubungan positif yang signifikan antara dukungan sosial dan SWB pada remaja. Temuan ini menunjukkan bahwa semakin tinggi 
dukungan sosial yang diberikan, maka SWB pada remaja akan meningkat. Temuan ini konsisten dengan hasil riset Tarigan (2018), yang menyimpulkan bahwa di kalangan remaja yang tinggal bersama orang tua tunggal dukungan sosial berhubungan positif dengan SWB. Riset dari Goodwin dan Plaza (2000) di Spanyol juga menemukan bahwa budaya kolektif mempengaruhi dukungan sosial yang diberikan, dimana dukungan dari keluarga sangat mempengaruhi SWB individu. Selanjutnya, hasil penelitia ini juga selaras dengan penelitian Lutfiyah (2018) yang menemukan bahwa dukungan sosial berkorelasi positif dengan aspek kepuasan hidup dan afek positif.

Konsep atau konstruk lain yang tidak diikutsertakan dalam penelitian ini tetapi yang berpotensi menentukan SWB pada remaja berdasarkan penelitian sebelumnya diantaranya adalah kepribadian (Grant dkk., 2009), family funtion (Sari \& Dahlia, 2018), school connectedness (Cunsolo, 2017), dan romantic relationship (Demirtas dkk., 2012).

Jenis kelamin juga dipertimbangkan dalam penelitian ini dengan beberapa alasan. Pertama, dalam budaya Minangkabau wanita memiliki lima aspek keistimewaan dibandingkan kaum pria, yaitu keturunan berdasarkan garis keibuan, sumber penghasilan yang diprioritaskan pada kaum wanita, wanita sebagai penyimpan hasil perekonomian, rumah bermukim, dan wanita memiliki hak dalam musyawarah (Wahyudi, 2018). Hasil analisis membuktikan tidak adanya pengaruh signifikan jenis kelamin baik terhadap dukungan sosial maupun SWB remaja beretnis Minang. Ronen dkk. (2016) juga melaporkan hasil yang sama bahwa jenis kelamin tidak menentukan MEDIAPSI | 2021, Vol. 7, No. 1, 76-88 tingkat SWB pada remaja. Sementara itu, Khairudin dan Mukhlis (2019) menemukan bahwa wanita mendapatkan dukungan sosial lebih tinggi dibandingkan laki-laki, tetapi wanita maupun laki-laki tidak berbeda dari segi tingkat SWB mereka.

Peneliti menyimpulkan bahwa meskipun terdapat keistimewaan yang diberikan pada wanita Minang, hal ini tidak mempengaruhi perolehan dukungan sosial yang diberikan dan SWB yang dimiliki serta sebaliknya. Bagi remaja, memiliki subjective well-being yang memadai adalah hal penting, karena menurut Gelhaar dkk. (2007), masa remaja merupakan masa transisi baik dalam konsteks sosial maupun budaya. Sebagai implikasinya, remaja perlu memiliki tingkat SWB yang memadai, yang mempermudah proses adaptasi dengan lingkungan sosial mereka (Balk dkk., 2011).

Penelitian ini juga menemukan bahwa remaja etnis Minang memiliki SWB pada kategori tinggi dan sedang. Selain itu, tidak ada remaja dalam penelitian ini yang memiliki SWB berkategori rendah. Kesimpulannya, tingkat SWB remaja dari keluarga etnis Minang bisa dinyatakan sangat memadai.

Dukungan sosial memiliki pengaruh besar terhadap SWB remaja. Mengafirmasi hal ini, Leme dkk. (2015) menyatakan bahwa dukungan sosial merupakan prediktor kuat yang mempengaruhi SWB remaja. Brajša-Žganec dkk. (2018) menemukan bahwa remaja yang mendapatkan dukungan sosial yang mencukupi dari teman memiliki tingkat SWB yang lebih tinggi dibandingkan remaja yang mendapatkan dukungan sosial yang mencukupi dari teman. Terakhir, 
Brannan dkk. (2013) menyatakan bahwa dukungan sosial dari keluarga memiliki pengaruh yang besar terhadap SWB remaja.

Dalam penelitian ini, mayoritas remaja Minang mempunyai tingkat dukungan sosial yang tinggi, sehingga dapat dikatakan bahwa remaja dari keluarga beretnis Minang memperoleh dukungan sosial yang memadai dari lingkungan keluarga, teman, maupun significant other. Terlepas dari hasil temuan yang diperoleh, penelitian ini memiliki beberapa keterbatasan. Pertama, dukungan sosial memiliki tiga aspek utama, yaitu dukungan sosial yang berasal dari keluarga, teman, dan significant other. Meskipun demikian, penelitian ini tidak membahas secara rinci dukungan sosial dalam bentuk apakah yang paling berpengaruh terhadap SWB pada remaja beretnis Minang. Kedua, faktor geografi seperti letak wilayah dan faktor demografi seperti suku juga perlu dipertimbangkan. Pertimbangan ini sesuai dengan konteks

\section{Daftar Pustaka}

Andrews, F. M., \& Withey, S. B. (1976). Social indicators of well-being: Americans' perceptions of life quality. Plenum.

Azwar, S. (2012). Penyusunan skala psikologi. Pustaka Belajar.

Balk, D. E., Zaengle, D., \& Corr, C. A. (2011). Strengthening grief support for adolescents coping with a peer's death. School Psychology International, 32(2), 144-162. https://doi.org/10.1177/0143034311400826

Brajša-Žganec, A., Kaliterna Lipovčan, L., \& Hanzec, I. (2018). The relationship dalam penelitian ini karena masyarakat Sumatera Barat memiliki adat dan suku yang beragam, dengan letak wilayah yang juga beragam antara pesisir pantai dan pegunungan. Faktor geografi dan demografi etnis tersebut berpotensi memiliki pengaruh terhadap tingkat dukungan sosial dan SWB pada remaja beretnis Minang, sebuah ide yang bisa diuji dalam penelitian lanjutan.

\section{Kesimpulan}

Hasil penelitian mengimplikasikan pentingnya dukungan sosial karena perannya dalam meningkatkan subjectivewell being (SWB) khususnya di kalangan remaja beretnis Minang di Sumatera Barat. Lingkungan sosial, baik teman, keluarga, dan pihak-pihak lain yang dianggap berperan penting atau significant other di Sumatera Barat dengan demikian hendaknya melakukan tindakan-tindakan yang bisa merawat bahkan meningkatkan dukungan sosial mereka terhadap remaja beretnis Minang di wilayah tersebut.

between social support and subjective well-being across the lifespan. Drustvena Istrazivanja, 27(1), 47-65. https://doi.or-g/10.5559/di.27.1.03

Brannan, D., Biswas-Diener, R., Mohr, C. D., Mortazavi, S., \& Stein, N. (2013). Friends and family: A cross-cultural investigation of social support and subjective well-being among college students. The Journal of Positive Psychology, 1(8), 65-75. https://doi.org/10.1080/174397$60 . \% 0 \mathrm{~A} 2012.743573$

Camara, M., Bacigalupe, G., \& Padilla, P. (2017). The role of social support in adolescents: Are you helping me or 
stressing me out? International Journal of Adolescence and Youth, 22(2), 123-136. https://doi.org/10.1080/02673843.2013 .875480

Cunsolo, S. (2017). Subjective wellbeing during adolescence: A literature review on key factors relating to adolescent's subjective wellbeing and education outcomes. Studi Sulla Formazione, 20(1), 81-94. https://doi.org/10.13128/Studi_Forma z-20941

Demirtas, S. C., \& Tezer, E. (2012). Romantic relationship satisfaction, commitment to career choices and subjective well-Being. ProcediaSocial and Behavioral Sciences, 46, 2542-2549.

https://doi.org/10.1016/j.sbspro.2012. 05.519

Diener, E., Emmons, R. A., Larsen, R. J., \& Griffin, S. (1985). The satisfaction with life scale. Journal of Personality Assessment, 49, 71-75. https://doi.org/10.1207/s15327752jpa 4901_13

Diener, E., Oishi, S., \& Lucas, R. E. (2015). National accounts of subjective well-being. American Psychologist, 70(3), 234-242. https://doi.org/10.1037/a0038-899

Diener, E., Seligman, M. E., Choi, H., \& Oishi, S. (2018). Happiest people revisited. Perspectives on Psychological Science, 13(2), 176184.

https://doi.org/10.1016/j.sbspro.2010. 03.602

Diener, E., Wirtz, D., Tov, W., KimPrieto, C., Choi, D. W., Oishi, S., \& Biswas-Diener, R. (2010). New wellbeing measures: Short scales to assess MEDIAPSI | 2021, Vol. 7, No. 1, 76-88 flourishing and positive and negative feelings. Social Indicators Research, 97(2), 143-156. https://doi.org/10.1007/s11205-0099493-y

Edosomwan, S., Prakasan, S. K., Kouame, D., Watson, J., \& Seymour, T. (2011). The history of social media and its impact on business. Management, 16(3), 79-91. https://www.researchgate.net/publicat ion/303216233_The_history_of_socia 1_media_and_its_impact_on_business

Fahmi, A. Z. (2019). Harapan ditinjau dari dukungan sosial pada remaja awal (Skripsi, Universitas Islam Indonesia).

https://dspace.uii.ac.id/handle/123456 789/14196

Firdaus, D. R. S., Lubis, D. P., Susanto, D., \& Soetarto, E. (2018). Potret budaya masyarakat Minangkabau berdasarkan keenam dimensi budaya Hofstede. Jurnal Sodality: Jurnal Sosiologi Pedesaan, 6(2). 121-130. https://core.ac.uk/download/pdf/2965 54067.pdf

Friedman, H. L. (1999). Culture and adolescent development. Journal of Adolescent Health, 25(1), 1-6. https://doi.org/10.1016/S1054139X(9 9)-00047-6

Gallagher, E. N., \& Vella-Brodrick, D. A. (2008). Social support and emotional intelligence as predictors of subjective well-being. Personality and Individual Differences, 44(7), 1551-1561.

https://doi.org/10.1016/j.paid.2008.01 .011

Gelhaar, T., Seiffge-Krenke, I., Borge, A., Cicognani, E., Cunha, M., Loncaric, D., .. \& Metzke, C. W. (2007). 
Adolescent coping with everyday stressors: A seven-nation study of youth from central, eastern, southern, and northern Europe. European Journal of Developmental Psychology, 4(2), 129-156. https://doi.org/10.1080/17405620600 831564

Ghozali, I. (2011). Aplikasi analisis multivariate dengan Program IBM SPSS 19. Badan Penerbit Universitas Diponegoro.

Goodwin, R., \& Plaza, S. H. (2000). Perceived and received social support in two cultures: Collectivism and support among British and Spanish students. Journal of Social and Personal Relationships, 17(2), 282291.

https://doi.org/10.1177\%2F02654075 00172007

Grant, S., Langan-Fox, J., \& Anglim, J. (2009). The big five traits as predictors of subjective and psychological well-being. Psychological Reports, 105(1), 205231.

https://doi.org/10.2466\%2FPR0.105.1 .205-231

Gülaçtı, F. (2010). The effect of perceived social support on subjective wellbeing. Procedia-Social and Behavioral Sciences, 2(2), 38443849.

https://doi.org/10.1016/j.sbspro.2010. 03.602

Hazen, E., Schlozman, S., \& Beresin, E. (2008). Adolescent psychological development: A review. Pediatrics in Review, 29(5), 161-168. https://doi.org/10.1542/pir.29-5-161

Hurlock, E. B. (2003). Psikologi perkembangan. Erlangga.
Jach, H. K., Sun, J., Loton, D., Chin, T. C., \& Waters, L. E. (2018). Strengths and subjective wellbeing in adolescence: strength-based parenting and the moderating effect of mindset. Journal of Happiness Studies, 19(2), 567-586. https://doi.org/10.1007/s1090201698 $41 \mathrm{y}$

Jumlah data satuan pendidikan [sekolah] per provinsi: Prov. Sumatera Barat. (2019). Kemdikbud.go.id. https://referensi.data.kemdikbud.go.id /index11.php?kode $=080000 \&$ level $=1$

Khairudin, K., \& Mukhlis, M. (2019). Peran religiusitas dan dukungan sosial terhadap subjective well-being pada remaja. Jurnal Psikologi, 15(1), 85-96.

https://doi.org/10.24014/jp.v15i1.712 8

Leme, V. B. R., Del Prette, Z. A. P., \& Coimbra, S. (2015). Social skills, social support and well-being in adolescents of different family configurations. Paideia, 25(60), 9-17. https://doi.org/10.1590/1-98243272560201503

Lutfiyah, N. (2018). Hubungan antara dukungan sosial dengan subjective well-being pada anak jalanan di wilayah Depok. Jurnal Psikologi, 10(2),

152-159.

https://ejournal.gunadarma.ac.id/inde x.php/psiko/article/view/1784/1543

Priyatno, D. (2013). Mandiri belajar analisis data dengan SPSS. Mediakom.

Proctor, C. (2014). Subjective well-being (SWB). Cmaj, 141(10), 1077-1079. https://doi.org/10.1007/97894007075 3-5

Ronen, T., Hamama, L., Rosenbaum, M., \& Mishely-Yarlap, A. (2016). 
Subjective well-being in adolescence:

The role of self-control, social support, age, gender, and familial crisis. Journal of Happiness Studies, 17(1), 81-104. https://doi.org/10.1007/s1090201495 855

Sangadji, E. M. S. (2010). Metodologi penelitian: Pendekatan Praktis dalam penelitian. Penerbit Andi.

Santrock, J. (2018). Life-span development. McGraw-Hill Higher Education.

Sarafino, E. P. (2002). Health psychology: Biopsychosocial interactions ( $4^{\text {th }}$ ed.). HN Wiley.

Sari, E. P., \& Dahlia, W. (2018). Family functioning and subjective well-being among adolescents. MOJPC:

Malaysia Online Journal of Psychology \& Counselling, 5(1), 4351.

http://jice.um.edu.my/index.php/MOJ C/article/view/10776/7539

Sherwell, C. (1977). Research report. Nature, 269(5629), Article 552. https://doi.org/10.1038/269552b0

Steinmayr, R., Wirthwein, L., Modler, L., \& Barry, M. M. (2019). Development of subjective well-being in adolescence. International Journal of Environmental Research and Public Health, 16(19). https://doi.org/10.3390/ijerph1619369 0

Sudarmanto, G. (2005). Analisis regresi linear berganda dengan SPSS. Graha Ilmu.

Sugiarti, H., \& Megawarni, A. (2012). Konsistensi koefisien determinasi sebagai ukuran kesesuaian model pada regresi robust. Matematika, Sains, Dan Teknologi, 13(2), 65-72. MEDIAPSI | 2021, Vol. 7, No. 1, 76-88 http://jurnal.ut.ac.id/index.php/jmst/ar ticle/view/484/472

Suh, E. M., \& Oishi, S. (2002). Subjective well-being across cultures. Online Readings in Psychology and Culture, 10(1), 1-11. https://doi.org/10.9707/23070919.1076

Tarigan, M. (2018). Hubungan dukungan sosial dengan subjective well-being pada remaja yang memiliki orangtua tunggal. Jurnal Diversita, 4(1), 1-8. https://doi.org/10.31289/diversita.v4i 1.1565

Tian, L., Zhao, J., \& Huebner, E. S. (2015). School-related social support and subjective well-being in school among adolescents: The role of selfsystem factors. Journal of Adolescence, $\quad 45$, 138-148. https://doi.org/10.1016/j.adolescence. 2015.09.003

Tov, W., \& Diener, E. (2013). Subjective wellbeing. The Encyclopedia of Cross-Cultural Psychology, 3, 12391245.

https://doi.org/10.1002/97811183398 93.wbeccp518

Utami, M. S., Praptomojati, A., Wulan, D. L. A., \& Fauziah, Y. (2018). Selfesteem, forgiveness, perception of family harmony, and subjective wellbeing in adolescents. International Journal of Research Studies in Psychology, 7(1), 59-72. https://doi.org/https://doi.org/10.5861 /ijrsp.2018.2006

Wahyudi, W. A. (2018). Perempuan Minangkabau dari konsepsi idealtradisional, modernisasi, sampai kehilangan identitas. INARXiv. https://doi.org/10.31227/osf.io/j2ead

Watson, D., Clark, L. A., \& Tellegen, A. 
(1988). Development and validation of brief measures of positive and negative affect: the PANAS scales. Journal of Personality and Social Psychology, 54(6), 1063-1070. https://doi.org/10.1037/00223514.54.6.1063

Winarsunu, T. (2012). Statistik dalam penelitian psikologi pendidikan. UMM Press.

Xi, X., Wang, Y., \& Jia, B. (2017). The Effect of social support on subjective well-being: Mediator Roles of selfesteem and self-efficacy. In 2017 3rd International Conference on Humanities and Social Science Research (ICHSSR 2017) (pp. 487499). Atlantis Press. https://doi.org/10.2991/ichssr17.2017.101

Yulanda, N. (2015). Pengaruh nilai budaya bisnis pada masyarakat Minangkabau terhadap perilaku kewirausahaan pedagang perantau di Tanah Abang.
Journal of Applied Business and Economics, 21(1), 95-108. https://journal.lppmunindra.ac.id/inde x.php/JABE/article/view/1457/1136

Yuliara, I. M. (2016). Modul regresi linier sederhana. Jurusan Fisika Fakultas Matematika dan Ilmu Pengetahuan Alam Universitas Udayana. https://simdos.unud.ac.id/uploads/file pendidikan_1_dir/3218126438990fa 0771ddb555f70be42.pdf

Zainal, A. (2014). Bundo kanduang (hanya) pemimpin di rumah (gadang). Antropologi Indonesia. 34(2), 124-133. https://doi.org/10.7454/ai.v34i2.3968 Zimet, G. D., Dahlem, N. W., Zimet, S. G., \& Farley, G. K. (2010). The multidimensional scale of perceived social support. Journal of Personality Assessment, 52(1), 3041. https://doi.org/10.1207/s15327752jp a5201_2 